\title{
Embryo implantation is closely associated with dynamic expression of proprotein convertase 5/6 in the rabbit uterus
}

\author{
Peter K Nicholls ${ }^{1,2+}$, Zhaogui Sun ${ }^{3 \dagger}$, Sophea Heng ${ }^{1}$, Ying Li ${ }^{1}$, Jian Wang ${ }^{3}$ and Guiying $\mathrm{Nie}^{1 *}$
}

\begin{abstract}
Background: Proprotein convertase 5/6 (PC5/6) is critical for embryo implantation in women, regulating both uterine epithelial receptivity and stromal cell decidualization. PC5/6 is likewise essential for implantation in mice, but involved only in decidualization. An alternative animal model is required to address the function of PC5/6 in the uterine epithelium. This study aimed to establish whether PC5/6 is associated with embryo implantation in rabbits.

Methods: Virgin New-Zealand white rabbits aged 3-4 moths were mated with males of the same strain, or pseudo-pregnancy induced. After mating, uterine tissues were collected over a 10 day (d) period $(n=3$ per time point) for RNA, protein and histological analyses to determine the temporal and spatial uterine expression pattern of PC5/6 during the initial stages of pregnancy or induced pseudo-pregnancy.
\end{abstract}

Results: PC5/6 mRNA was up-regulated just prior to embryo attachment on d6, and the elevated expression was maintained throughout implantation on $\mathrm{d6.5-10}$. Western analysis revealed a preferential up-regulation of PC5/6 in the implantation sites. Immunohistochemical analysis identified that both the amount and cellular localization of PC5/6 changed with increasing pregnancy stages. Before embryo attachment, PC5/6 was low and localised in the luminal and glandular epithelium. It increased on d6.5 in the basal glands and mucosal folds, and then strongly intensified on d7-10 in the multinucleated luminal symplasma and decidual cells at the site of embryo implantation. In contrast, the pseudo-pregnant uterus displayed relatively low and static PC6 mRNA expression throughout the 10 days, with no obvious changes in either PC5/6 level or cellular localization.

Conclusions: These findings demonstrate that embryo implantation in the rabbit is closely associated with dynamic expression of uterine $\mathrm{PC} 5 / 6$, and that the rabbit may be an appropriate model to investigate the function of PC5/6 in the uterine epithelium during embryo attachment.

\section{Background}

Embryo implantation is a complex process requiring a plethora of regulatory molecules, including proteases, cytokines and chemokines (reviewed in [1]). Failure of implantation accounts for approximately $75 \%$ of human pregnancy loss before 20 weeks of gestation, and is a major limiting factor in assisted reproduction $[2,3]$. Embryo implantation requires a healthy embryo and a receptive uterus that are synchronously developed. The

\footnotetext{
* Correspondence: guiying.nie@princehenrys.org

+ Contributed equally

'Prince Henrys Institute of Medical Research, 246 Clayton Road, Clayton,

Victoria 3168, Australia

Full list of author information is available at the end of the article
}

uterus must undergo significant morphological and physiological changes to prepare for implantation [1]. In humans, two uterine events critical for implantation are the establishment of epithelial receptivity and stromal cell decidualization [4].

The proprotein convertases (PCs) are a family of 7 proteases that endoproteolytically cleave latent precursor proteins into their biologically active states (reviewed in [5]). PCs generate a large number of tissue-specific and functionally important bioactive proteins, and as such, they act as regulatory "master switches" by influencing cell proliferation, motility, adhesiveness and invasion [5]. PCs have been associated with a number of human 
diseases, including cancer, and are recognised as potentially important therapeutic targets [5-7].

PC5/6 is the only PC member that is associated with uterine remodelling and important for embryo implantation. PC5/6 is up-regulated in the uterus specifically at implantation in the mouse and human [8-10]. In mice, PC5/6 is up-regulated specifically in decidualizing stromal cells adjacent to the implanting embryo at the time of attachment and implantation [9]. PC5/6 is the only $\mathrm{PC}$ involved in decidualization in mice [10]. In women, PC5/6 is likewise dramatically increased during decidualization prior to implantation and intensifies with implantation establishment $[11,12]$. In contrast to the mouse, PC5/6 is also expressed in the uterine epithelium across the menstrual cycle in women peaking during the receptive phase, in addition to the decidual cells [12]. PC5/6 is the only PC tightly regulated in this manner $[10,11,13]$. Therefore, PC5/6 is likely to be involved in the establishment of epithelial receptivity as well as stromal cell decidualization in the human uterus.

Knockdown of PC5/6 prevents decidualization of human endometrial stromal cells in culture [14], and blocking PC5/6 uterine production inhibits decidualization and embryo implantation in mice [12], proving $\mathrm{PC} 5 / 6$ is critical for decidualization. The precise mechanisms of PC5/6 action in the uterine epithelium remain to be determined. Given that $\mathrm{PC} 5 / 6$ primarily regulates decidualization in the mouse, mice are a powerful in vivo model to investigate the functions of PC5/6 in decidualization. However, major uterine epithelial differences exist between rodents and humans, including the presentation of cell surface glycosylation and selectin ligands $[15,16]$, and that PC5/6 is not expressed in the non-pregnant mouse uterine epithelium. Thus, an appropriate non-mouse animal model relevant to human implantation is required to investigate the in vivo function of PC5/6 in the uterine epithelium.

The rabbit is regarded as an excellent model to study the molecular events of embryo adhesion and attachment, as it employs a typical centric or fusion type of implantation in which the blastocyst adheres solely to the apical epithelial cells $[17,18]$. Given that rabbits are obligate ovulators, both pseudo-pregnancy and pregnancy can be precisely triggered, and ovulation $(10 \mathrm{~h}$ after mating or hormonal treatment), embryo apposition and attachment (day 6.5-7) precisely timed. Furthermore, the rabbit uterus undergoes a dramatic transformation in the days after ovulation, such that days 1-4 and 4-7 are in some degree analogous to the proliferative and secretory phases of the primate menstrual cycle, respectively [19]. Rabbits have been used previously to investigate molecules associated with embryo attachment and implantation, including integrins, osteopontin, epidermal growth factors, mucin 1 and leukaemia inhibitory factor [18,20-23].

This study aimed to establish whether uterine PC5/6 is associated with embryo implantation in rabbits. The temporal and spatial expression pattern of PC5/6 was determined in the rabbit uterus during early pregnancy and pseudo-pregnancy. Real-time RT-PCR and Western blot analysis examined PC5/6 mRNA and protein, respectively. The cellular localization and expression pattern were also determined by immunohistochemistry. The results demonstrate that uterine PC5/6 is dynamically regulated in the rabbit during implantation, especially in the epithelium, suggesting that the rabbit will provide a useful animal model to examine the roles of PC5/6 in uterine epithelium for embryo attachment.

\section{Methods \\ Animals}

New Zealand White rabbits aged 3-4 months (2.6-3.2 kg) were maintained at Shanghai Institute of Planned Parenthood Research Animal Facility under controlled conditions ( $14 \mathrm{~h}$ light- $10 \mathrm{~h}$ dark cycle, $22^{\circ} \mathrm{C}$ ) with free access to food and water. All experimentation was performed in compliance with the laboratory animal care protocols approved by the Institutional Animal Care Committee of the Shanghai Institute of Planned Parenthood Research.

Virgin female rabbits were mated with males of the same strain, with the time of mating designated as day (d) 0 of pregnancy. Animals were euthanased at various time points following mating $(\mathrm{d} 0,1,3,5,6,6.5,7,8$ and $10, \mathrm{n}=3$ each) by injecting $20 \mathrm{ml}$ air into the auricular veins. To induce pseudo-pregnancy, rabbits received an i.m. injection of $20 \mathrm{IU}$ pregnant mare serum gonadotrophin, and $72 \mathrm{~h}$ later, an i.m. injection of $0.8 \mu \mathrm{g}$ of gonadotrophin-releasing hormone $(\mathrm{GnRH})$. Ovulation was confirmed in each animal by the presence of the corpus luteum in each ovary.

Uterine tissues were collected at each time point, and either snap-frozen in liquid nitrogen for RNA and protein analysis, or fixed in $4 \%$ paraformaldehyde (in $0.1 \mathrm{M}$ sodium phosphate buffer $\mathrm{pH}$ 7.4) for $48 \mathrm{~h}$ followed by paraffin-embedding for immunohistochemistry. From the pregnant rabbits, implantation (Imp) and interimplantation (Inter) site tissues were collected separately for RNA (d6.5 onwards, $\mathrm{n}=3$ ) and protein (d7.5 onwards) analysis.

\section{RNA isolation and real-time PCR analysis}

Total RNA was extracted using Trizol reagent (Invitrogen, Carlsbad, CA) as per the manufacturer's instructions. Contaminating DNA was removed using a DNAse free kit (Ambion, Austin, TX). RNA quality and quantity was assessed by optical densitrometry (Nanodrop, ThermoFisher Scientific, Waltham MA). Reverse transcription 
was performed using $500 \mathrm{ng}$ RNA with SuperScript VILO cDNA synthesis kit (C\#11754, Invitrogen, Carlsbad, CA), and the resulting products were snap-frozen and stored at $-80^{\circ} \mathrm{C}$.

Quantitative real-time PCR analysis was performed using the Corbett Rotorgene 3000 (Corbett Lifesciences, Sydney, Australia) with the FastStart DNA Master SYBR-Green 1 system (Roche Applied Sciences, Basel, Switzerland). Oligonucleotide sequences and conditions for PC5/6 and $18 \mathrm{~S}$ amplicons are shown in Table 1. For quantification, a reference cDNA was prepared from a rabbit uterine tissue for quality control and standard. After 38 cycles, a melting curve analysis was performed to monitor PCR product purity. In initial experiments, amplification of a single PCR product was confirmed by agarose gel electrophoresis and DNA sequencing. Data was normalised to $18 \mathrm{~S}$ and the mean from each triplicate samples from three animals were compared.

\section{Western blot analysis}

Frozen uterine tissues were thawed and homogenized using a glass homogenizer in extraction buffer, containing $6.0 \%(\mathrm{w} / \mathrm{v}) \mathrm{SDS}, 0.14 \mathrm{~mol} / \mathrm{L}$ Tris- $\mathrm{HCl}(\mathrm{pH} 6.8)$, $22.4 \%(\mathrm{v} / \mathrm{v})$ glycerol, soybean trypsin inhibitor $(10 \mu \mathrm{g} /$ $\mathrm{mL}$, Sigma, St. Louis, MO), PMSF (1 mmol/L, Sigma,), leupeptin and aprotinin $(10 \mu \mathrm{g} / \mathrm{mL}$ each, Amresco, Solon, $\mathrm{OH})$. The homogenates were centrifuged $(14,000 \mathrm{~g} / 10 \mathrm{~min})$ at $4{ }^{\circ} \mathrm{C}$, the supernatant containing proteins was collected and protein concentrations were determined using the Bradford assay. Proteins $(50 \mu \mathrm{g})$ were subjected to reducing $12 \%$ sodium dodecyl sulfatepolyacrylamide gel electrophoresis (SDS-PAGE) and transferred onto nitrocellulose membranes (ImmobilonTM-NC, Millipore Corporation, Billerica, MA, USA). The membrane was blocked for $1 \mathrm{~h}$ in $5 \%$ skim milk in 0.2\% Tween-20 (Sigma, St. Louis, MO, USA), and probed overnight at $4^{\circ} \mathrm{C}$ with a previously characterized affinity purified polyclonal sheep anti-human PC5/6 antibody $(25 \mu \mathrm{g} / \mathrm{ml}$ in blocking solution, Nie et al., $2005 \mathrm{~b})$. The membrane was incubated for $1 \mathrm{~h}$ with HRP-conjugated donkey anti-sheep IgG (Milllipore, Billerica, MA, 1:10,000 dilution in blocking solution) at room temperature, and the signal visualized by chemiluminescent detection (Thermo Scientific, Rockford, IN).
The membrane was subsequently stripped and re-probed with a $\beta$-actin antibody (Cell Signaling, Danvers, MA).

\section{Immunohistochemical analysis}

Immunohistochemistry was performed using the sheep PC5/6 antibody ( $\mathrm{n}=3$ sites per animals, $\mathrm{n}=3$ animals for each time point) as previously described [8]. Briefly, formalin-fixed paraffin sections $(5 \mu \mathrm{m})$ were de-waxed in histosol (Sigma), rehydrated, and subjected to antigen retrieval by microwave $(5 \mathrm{~min} / 700 \mathrm{~W}$ followed by $5 \mathrm{~min} /$ $140 \mathrm{~W})$ in $0.01 \mathrm{~mol} / \mathrm{L}$ sodium citrate buffer $(\mathrm{pH} 6.0)$. Endogenous peroxidase activity was quenched with $6 \%$ $\mathrm{H}_{2} \mathrm{O}_{2}$ (diluted $1: 1 \mathrm{v} / \mathrm{v}$ in $100 \%$ methanol) for $10 \mathrm{~min}$ at room temperature. Nonspecific binding was blocked by incubation with 15\% normal rabbit serum and 5\% fetal calf serum in TBS containing $0.1 \%$ Tween-20. Primary antibody was applied $(10 \mu \mathrm{g} / \mathrm{mL})$ at $37{ }^{\circ} \mathrm{C}$ for $2 \mathrm{~h}$. Following washing in TBS, slides were incubated with biotinylated rabbit anti-sheep IgG (1:200 dilution, Vector Laboratories, Burlingame, CA) for $30 \mathrm{~min}$ at room temperature. Signal was amplified using Vectastain ABC amplification (Vector Laboratories) for $30 \mathrm{~min}$ and positive localization visualized using the peroxidise substrate 3, 3'-diaminobenzidine (DAB, Dako, Kingsgrove, Australia) which produced a brown precipitate. Tissue sections were counterstained with Harris' hematoxylin (Sigma Chemicals, St Louis, MO), dehydrated, and mounted with DPX (ProSciTech, Thuringowa, Australia). Negative controls were included for each section, where preimmune sheep IgG was substituted for the primary antibody at a matching concentration. The localization of staining was assessed by two investigators who noted expression patterns, for which representative images were recorded.

\section{Statistics}

Unless otherwise noted, all measurements were on samples from three separate animals, from which the mean and SEM were calculated. All statistics were performed using SigmaStat version 3.5 (Systat Software, Inc., San Jose, CA). Homogeneity of variance was assessed for all groups by normality and equal variance tests. Experiments in which variation followed a normal distribution were assessed using a one-way ANOVA, followed by the

Table 1 Primer sequences and conditions used for quantitative PCR analysis

\begin{tabular}{|c|c|c|c|c|c|}
\hline Gene Name & Primer Sequence $\left(5^{\prime}-3^{\prime}\right)$ & Size (bp) & Anneal temp $\left({ }^{\circ} \mathrm{C}\right)$ & Extension time (s) & $\begin{array}{r}\mathrm{Mg} 2+ \\
(\mathrm{mM})\end{array}$ \\
\hline PC5/6 & $\begin{array}{l}\text { F: TCTGACCTGGAGAGACGTAC } \\
\text { R: TGTCTTGATATGTCGATCTG }\end{array}$ & 221 & 55 & 9 & 3.0 \\
\hline $18 \mathrm{~S}$ & $\begin{array}{l}\text { F: CGGCTACCACATCCAAGGAA } \\
\text { R: GCTGGAATTACCGCGGCT }\end{array}$ & 187 & 64 & 8 & 3.0 \\
\hline
\end{tabular}

F, Forward; R, Reverse. 
Student-Newman-Keuls post hoc multiple group comparisons test for significance. $P$ value of $\leq 0.05$ was used as a cut-off for statistical significance.

\section{Results}

\section{RT-PCR analysis of PC5/6 mRNA in the rabbit uterus} during early pregnancy

Primers specific to the rabbit PC5/6 mRNA (both A and $\mathrm{B}$ isoforms) coding region were designed and conditions for RT-PCR optimized (Table 1). Amplification of $18 \mathrm{~S}$ was used for data normalization. A single band of expected size was amplified for PC5/6 (221 bp) and 18S (187 bp) from rabbit uterine RNA (Figure 1A). Melting curve analysis validated each band as a single DNA product (data not shown). No amplification occurred in the negative controls when either the reverse transcriptase

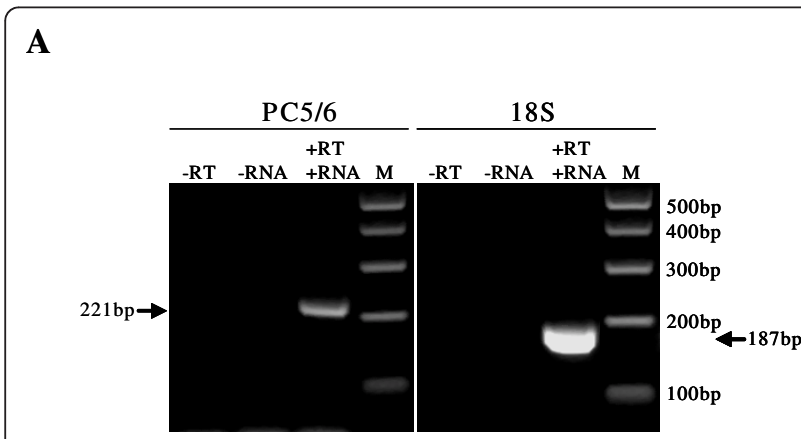

$\mathbf{B}$

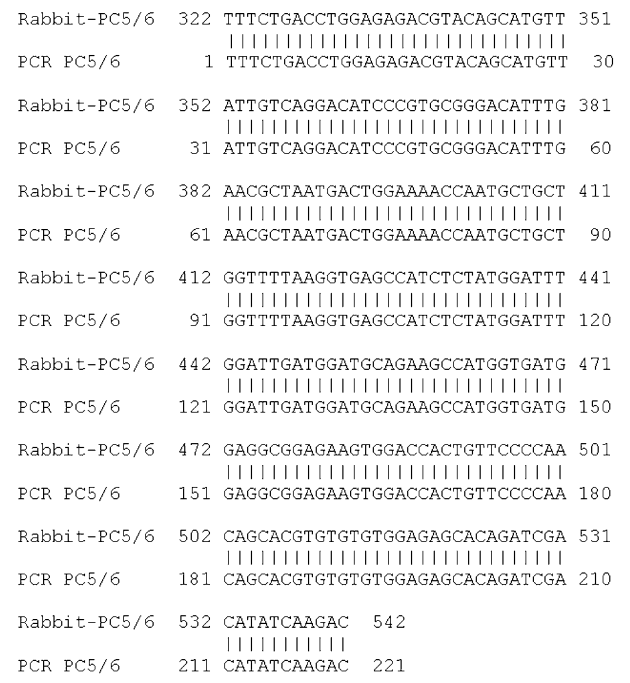

Figure 1 RT-PCR confirmation of PC5/6 mRNA expression in the rabbit uterus. (A) Agarose gel electrophoresis of RT-PCR products of PC5/6 (220 bp) and 18S (187 bp) respectively. Two negative controls are: -RT, no reverse transcription enzyme in RT reaction; -RNA, no RNA in RT reaction. +RT+RNA, RT reaction contained RNA and reverse transcription enzyme. M, DNA marker. (B) Comparison between sequences of rabbit PC5/6 mRNA (RabbitPC5/6) and RT-PCR amplified uterine PC5/6 product (PCR-PC5/6). or RNA was omitted (Figure $1 \mathrm{~A}$ ). The PC5/6 product was sequenced and found to be $100 \%$ homologous to the rabbit PC5/6 mRNA (Figure 1B), confirming specificity. This established that PC5/6 mRNA was expressed in the rabbit uterus, and that the newly designed primers were specific and suitable for analysing PC5/6 mRNA in the rabbit.

The expression of PC5/6 mRNA in the rabbit uterus during early pregnancy and pseudo-pregnancy was analysed by quantitative RT-PCR. The first 10 days of pregnancy including the period of embryo attachment (d6.5-7) and implantation (d8-10) were examined. For each real-time run, the cycle threshold was determined for replicates of each sample and compared to the linear standard curve, then normalised to $18 \mathrm{~S}$ expression. The mean and SEM were then determined for each triplicate of animals and are presented in Figure 2. Pseudopregnant rabbits showed no significant changes in PC5/ 6 expression across the 10 days following $\mathrm{GnRH}$ administration. In contrast, the pregnant uterus displayed a dynamic pattern of $\mathrm{PC} 5 / 6$ expression during the same time-course (Figure 2). PC5/6 mRNA levels were relatively static during the initial 5 days (except a nonsignificant increase on $\mathrm{d} 1$ ), but a sustained trend of increased expression in pregnant tissues commenced from d6 (immediately prior to implantation, 1.9 fold greater than $\mathrm{d} 0$ level). On d6.5, corresponding to the time of initial embryo attachment, the mean level at the implantation and inter-implantation sites compared to d0 was 2.34 and 1.82 fold respectively. These increased levels were maintained throughout $\mathrm{d} 6.5-8$ at both the implantation or inter-implantation sites, and on d10 at the inter-implantation sites (Figure 2).

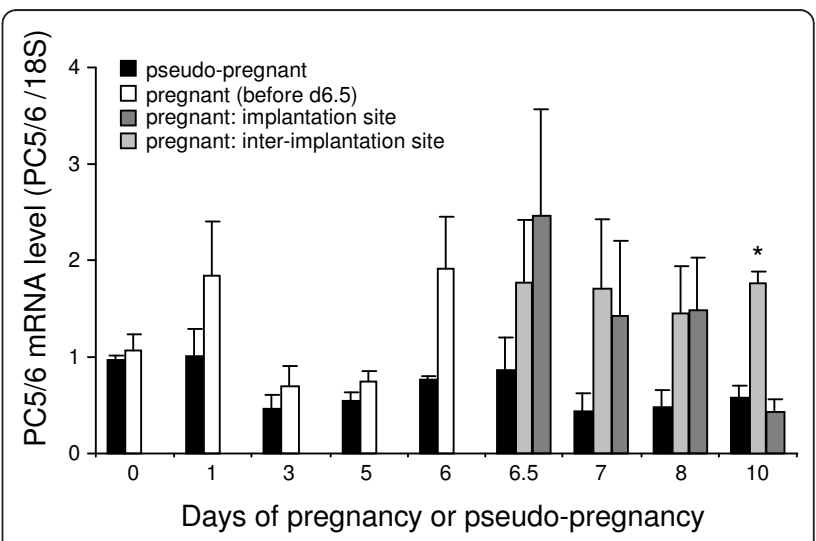

Figure 2 Real-time RT-PCR analysis of PC5/6 mRNA expression in the rabbit uterus between $\mathrm{d} 0$ and $\mathrm{d} 10$ in pregnant and pseudo-pregnant animals. For pregnant uterus from d6.5 onwards, implantation and inter-implantation sites were collected separately. Data are mean + SEM, $\mathrm{n}=3$ animals, ${ }^{*} \mathrm{P}<0.001$ (inter-implantation site vs implantation site and pseudo-pregnant uterus on the same day). 
When pregnant and pseudo-pregnant animals were compared at the equivalent time points, no significant difference in PC5/6 mRNA levels was found during d0-5 (Figure 2). However, from d6 onwards the expression of PC5/6 was found to be higher in the pregnant uterus. On d6, the pregnant uterus was 2.5 fold of the pseudo-pregnant counterpart (Figure 2). On d6.5 (the putative time of embryo attachment), the fold differences were 2.9 and 2.1 for the implantation and interimplantation sites compared to the pseudo-pregnant uterus, respectively. This trend was maintained between d6.5-8, with a peak difference between the pregnant and pseudo-pregnant uteri on $\mathrm{d} 7$ of 3.2- and 3.9-fold in the implantation and inter-implantation sites, respectively (Figure 2). On d10, PC5/6 levels in the inter-implantation sites were 3.0 fold greater than the pseudo-pregnant value ( $\mathrm{p}<0.001$, Figure 2 ). This data reveals that PC5/6 expression is increased in the rabbit uterus at the time of embryo attachment and implantation, and that this dynamic regulation was specific to pregnancy.

\section{Western blot analysis of PC5/6 protein in the rabbit uterus during implantation}

The presence of PC5/6 protein in the rabbit uterus was established by Western blot analysis. Total proteins isolated from implantation and inter-implantation sites on d7-10 were probed with the PC5/6 antibody. The membrane was then re-probed for $\beta$-actin as a loading control (Figure 3). Two bands at approximately $66 \mathrm{kDa}$ were detected for PC5/6 in all samples, consistent with previous findings in the mouse $[8,24]$. A much higher level of both bands of $\mathrm{PC} 5 / 6$ protein was detected in $\mathrm{d} 8$ and d10 isolates than d7 (Figure 3) Furthermore, the expression of PC5/6 protein was more intense in the implantation than the inter-implantation sites at each time point (Figure 3). The prevalence of truncated

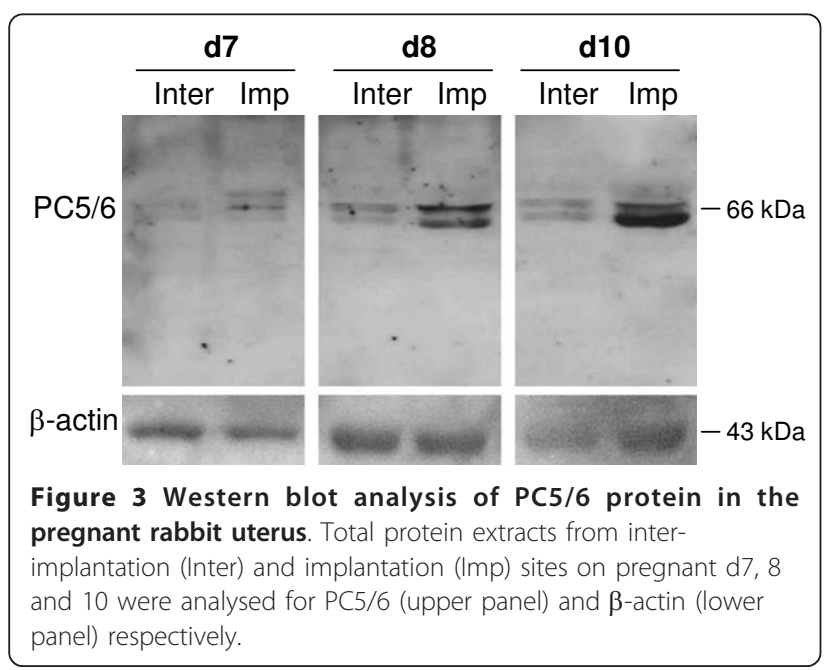

forms of PC5/6 may represent an additional regulatory mechanism in the rabbit uterus. These data confirmed the specificity of the PC5/6 antibody in the rabbit uterus, and demonstrated that PC5/6 protein was increased during embryo implantation.

\section{Immunolocalization of $\mathrm{PC} 5 / 6$ protein in the rabbit uterus during early pregnancy}

The cellular localization and expression pattern of PC5/ 6 protein in the rabbit uterus across early pregnancy and pseudo-pregnancy was then determined by immunohistochemistry using formalin-fixed tissues and the PC5/6 antibody previously validated by Western blot. In the pregnant uterus, between $\mathrm{d} 0-1$ of pregnancy (Figure 4A-C), endometrial stroma and luminal epithelium demonstrated low levels of immuno-reactive PC5/ 6. The basal regions of luminal epithelium folds were also PC5/6 positive (Figure $4 \mathrm{~B}-\mathrm{C}$ ), and to a lesser extent, positivity was also observed in the endothelial cells (Figure 4B-C). Between d3-5 (Figure 4D-F), the endometrial cells proliferate extensively, leading to the formation of mucosal folds. During this period, little immuno-reactive PC5/6 was detected in the endometrial folds (Figure 4E). In contrast, the deep glands located in the crypts against the myometrium were clearly positive (Figure 4F). At the time of embryo attachment on day 6.5 (Figure 4G-I), PC5/6 positivity in the deep basal glands became more prominent (Figure 4I). At this point of uterine remodelling, the mucosal folds were further extended compared with the early stages and were positive for PC5/6 (Figure 4G-H).

PC5/6 levels and localization transformed significantly during the time of embryo attachment and implantation (Figure 5). Immediately after initial embryo attachment on d7 (Figure 5A-C), PC5/6 was differentially expressed between the attachment (antimesometrial side) and nonattachment regions (mesometrial side). Whilst the mesometrial folds maintained PC5/6 immuno-negativity (Figure $5 \mathrm{C}$ ), the antimesometrial luminal epithelium closely apposed to the blastocyst, now fusing, becoming multinucleated and transforming to a structure termed symplasma, became PC5/6 immuno-positive (Figure 5B). This pattern of localization persisted with gestation, and the intensity of immuno-reactive PC5/6 increased progressively (Figure 5). By d8 (Figure 5D-F), PC5/6 staining was much stronger than on $\mathrm{d} 7$ in the symplasma (Figure 5E). Noticeably, the staining was polarized within the multinucleated symplasma, with a prominent accumulation of $\mathrm{PC} 5 / 6$ protein at the basal surface (Figure $5 \mathrm{E}$ ). On d10, very strong PC5/6 staining was detected at the site of embryo implantation (Figure 5G$5 \mathrm{H})$. Strong immuno-reactive PC5/6 was seen in the multinucleated luminal epithelium cells (Figure $5 \mathrm{H}$ ), which now appeared to be evenly distributed, rather 


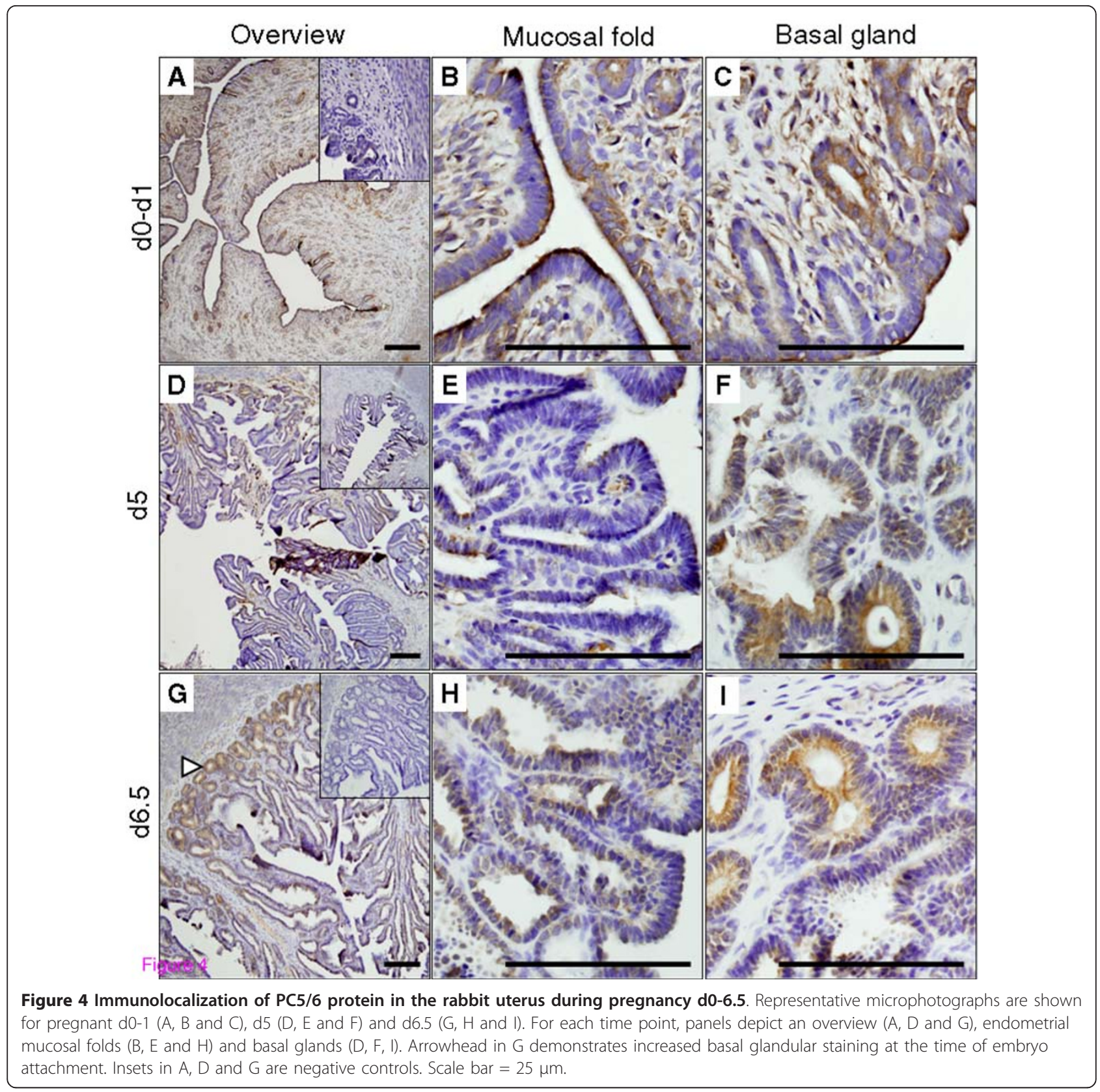

than polarised. In addition, strong PC5/6 staining was evident in the peri-vascular decidual cells (Figure $5 \mathrm{H}$, arrow head and insert). The luminal epithelium and glandular epithelium away from the implantation site maintained PC5/6 negativity (Figure $5 \mathrm{I}$ ), but positivity was evident in the stroma of this region.

The uteri of pseudo-pregnant rabbits ( $\mathrm{d} 0$ - $\mathrm{d} 10)$ were also examined by immunohistochemistry. The morphological changes during pseudo-pregnant d0-5 resembled those of pregnant rabbits on the equivalent days (data not shown). Likewise, uterine PC5/6 expression and localization were similar between pregnant and pseudo- pregnant rabbits during this period ( $\mathrm{d} 0-5$, data not shown). However, unlike the pregnant uterus, the pseudo-pregnant uterus showed no further uterine remodelling with increasing gestation after $\mathrm{d} 5$. While a significant increase in PC5/6 staining was detected specifically at implantation sites in the pregnant uterus, no such changes were observed in the epithelial cells during pseudo-pregnancy, and PC5/6 levels and localization in the pseudo-pregnant uterus on $\mathrm{d} 8-10$ were similar to that of d5 pregnant uterus. Example images of PC5/6 immunolocalization in $\mathrm{d} 8$ pseudo-pregnant uterus are shown in Figure 5J-L. 


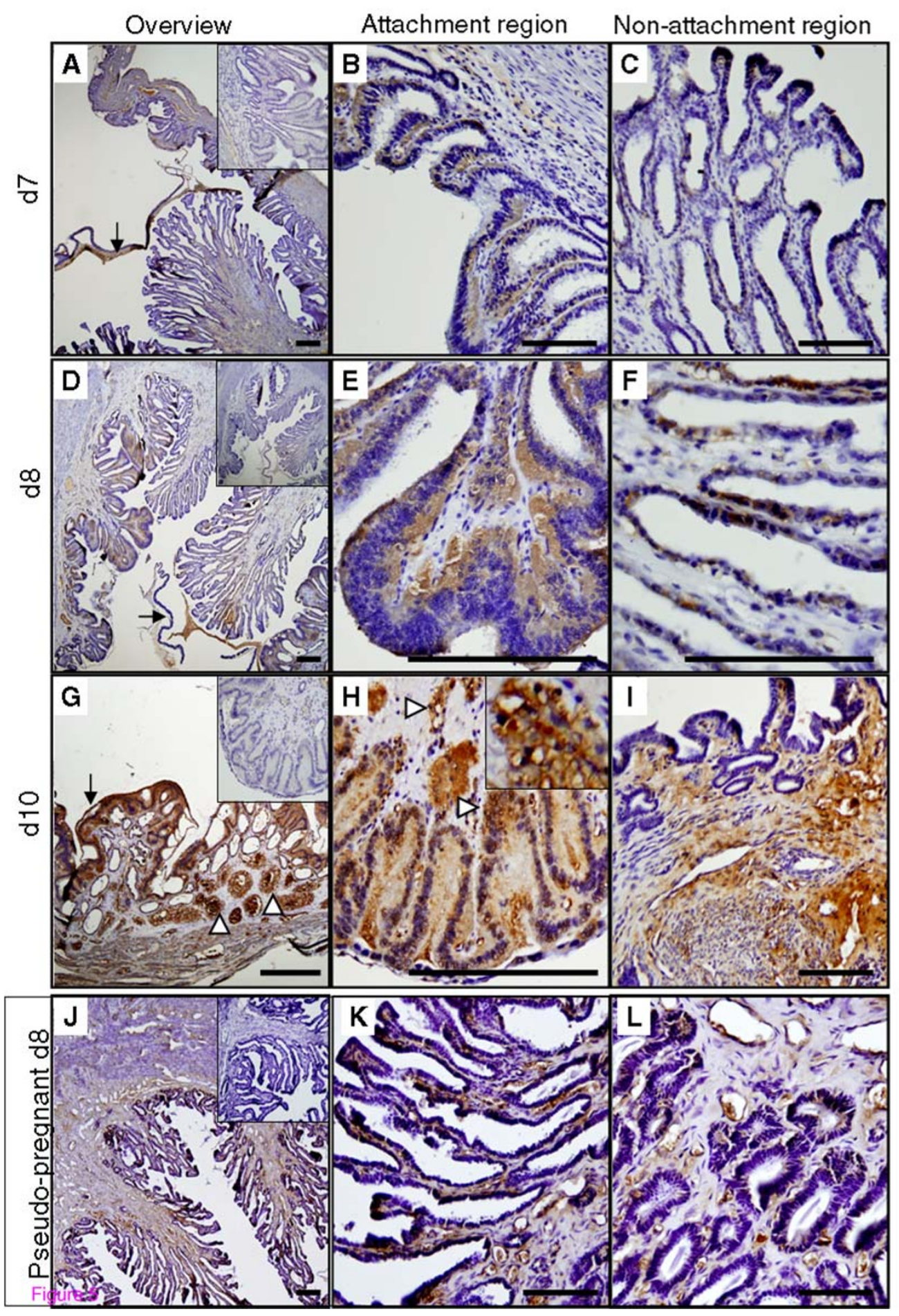

Figure 5 Immunolocalization of PC5/6 protein in the rabbit uterus on pregnant d7-10 and pseudo-pregnant d8. Representative microphotographs are shown for pregnant uterus on $d 7(A, B$ and $C), d 8(D, E$ and $F)$ and $d 10(G, H$ and $I)$, and pseudo-pregnant uterus on $d 8$ $(J, K$ and $L)$. For pregnant uterus, panels depict an overview $(A, D, G)$, attachment region $(B, E$ and $H)$ and non-attachment region $(D, F$ and $I)$ for each time point. Arrows in A, D and $\mathrm{G}$ highlight the embryonic tissues. Arrowheads in $\mathrm{H}$ show decidual cells; the insert shows a higher magnification. For pseudo-pregnant uterus, an overview (J), mucosal folds $(K)$ and deep basal glands (I) are shown. Inserts in $A, D, G$ and J are negative controls. Scale bar $=25 \mu \mathrm{m}$. 
Collectively, this data establishes that PC5/6 protein is dynamically regulated during early pregnancy in the rabbit uterus. PC5/6 was up-regulated in the endometrial deep glands just prior to embryo attachment. PC5/6 localization then strongly intensified in the multinucleated luminal symplasma and decidual cells at the site of embryo attachment during the time of implantation. PC5/6 up-regulation was both pregnancy, and implantation-site specific.

\section{Discussion}

This study established that dynamic expression of PC5/6 in the rabbit uterus is closely associated with embryo implantation and pregnancy. Uterine PC5/6 mRNA was up-regulated just prior to embryo attachment on d6 of pregnancy, which was maintained throughout implantation between d6.5-10. In contrast, no such changes were observed in the pseudo-pregnant rabbits as they displayed a low and static PC5/6 mRNA level throughout the 10 days of pseudo-pregnancy. Western blot analysis revealed a preferential up-regulation of PC5/6 protein at embryo implantation sites. Immunohistochemical analysis confirmed this pattern and illustrated that PC5/6 protein level and cellular localization changed according to pregnancy stage. Prior to embryo attachment, PC5/6 expression is low and localised primarily in the luminal epithelium and endometrial glands. Subsequently, PC5/6 expression increased in the deep basal glands and mucosal folds just prior to embryo attachment, and then strongly intensified in the multinucleated luminal symplasma and decidual cells at the site of embryo implantation from d7-10. In contrast, no obvious change in either PC5/6 expression or cellular localization occurred across 10 days of pseudo-pregnancy. This study thus demonstrates that uterine PC5/6 up-regulation is pregnancy-stage, and implantation-site specific.

The overall pattern and cellular localization of PC5/6 in the rabbit uterus during early pregnancy is more analogous to that of the human than the mouse. In both the human and mouse uterus, PC5/6 is specifically expressed in the decidual cells in the stromal compartment, but glandular and luminal epithelial expression is only observed in the human uterus $[8,9]$. This study identified uterine PC5/6 expression in both the epithelium and decidual cells in the rabbit, as in the human, establishing the basis for using the rabbit as a model system to investigate the function of PC5/6 in the uterine epithelium. It is worth noting that in the rabbit uterus, even though the degree of stromal decidualization is minimal, decidualizing cells at the implantation site clearly expressed PC5/6, making decidual PC5/6 expression a common feature among mice, rabbits and humans.

Rabbit implantation employs a typical fusion type of implantation in which the blastocyst adheres solely to the luminal epithelial cells [17]. Distinct up-regulation and immunolocalization of PC5/6 in the uterine epithelium at the site of implantation from the very early stages of attachment strongly indicates a role for epithelial PC5/6 in blastocyst adhesion. The apical surface of the endometrial epithelium is constitutively non-adhesive (thus nonreceptive) except during implantation. Conversion from a non-receptive to receptive state requires the epithelial cell acquisition of surface components required for receptor-ligand interactions, and alterations/modifications to adhesion molecules. During receptivity, the apical glycocalyx is reduced, and the normally abundant apical microvilli gradually retract, generating a flattened epithelial surface for blastocyst adhesion [25]. PC5/6 is known to endo-proteolytically activate a number of important adhesion molecules including neural adhesion protein-L1 [26] and integrins [27,28]. Of note, the intergrins are among the best characterized markers of uterine receptivity in a number of species including the rabbit [25]. Indeed, functional studies have confirmed that the $\alpha_{v} \beta_{3}$ integrin complex is important for implantation in the rabbit [22]. It is thus possible that PC5/6 mediates integrin activation in the epithelium for embryo attachment and implantation in the rabbit.

PC5/6 can interact with heparin sulfate proteoglycans (HSPGs), thereby recruiting itself to the cell surface to activate a number of HSPG-binding proteins at the cell periphery or in the extracellular space $[29,30]$. HSPGs and HSPG-binding proteins participate in cell adhesion during implantation [25]. One such HSPG molecule is heparin-binding EGF-like growth factor (HB-EGF), whose expression is dramatically increased during pregnancy and restricted to implantation sites [31]. Since PC5/6 has been suggested activate HB-EGF on the cell surface $[29,30]$, it is likely that PC5/6 regulates adhesion molecules and other cell surface proteins, in the endometrial epithelium during embryo attachment.

Pseudo-pregnancy is commonly used to investigate whether the expression of a particular gene is hormonedependent or requires the presence of a blastocyst. This study suggests that $\mathrm{PC} 5 / 6$ regulation in the rabbit uterus is complex and pregnancy-specific. Prior to embryo attachment, PC5/6 expression and localization was comparable between pregnant and pseudo-pregnant uteri. Immediately prior to initial embryo attachment, PC5/6 mRNA was specifically up-regulated in the pregnant uterus, and PC5/6 protein was distinctly localised at the site of embryo attachment. This pattern of expression is consistent in principle with mouse and human studies. In the mouse, PC5/6 is up-regulated only at the site of embryo attachment, and this expression intensifies with increasing implantation stages [9]. In the human, PC5/6 expression in the decidual cells increases with implantation establishment [8]. Further studies are needed to 
address the contribution of the blastocyst and/or the blastocyst-endometrium interaction to promote PC5/6 expression. Future studies are required to determine the importance of PC5/6 in implantation in the rabbit, by direct inhibition of $\mathrm{PC} 5 / 6$ production or activity in the rabbit uterus in vivo.

\section{Conclusions}

In summary, our studies have demonstrated that rabbit uterine PC5/6 expression is intimately associated with pregnancy and embryo implantation. Uterine PC5/6 expression is dynamically regulated in pregnancy, and distinctively expressed at the site of embryo attachment, supporting an essential role for this molecule in embryo attachment and implantation. Therefore, this study has established that the rabbit will be a valuable in vivo model to investigate the physiological role of PC5/6 in the uterine epithelium for embryo attachment and implantation.

\section{Abbreviations}

PC5/6: pro-protein convertase 5/6; Inter: inter-implantation site; Imp: implantation site.

\section{Acknowledgements \\ The authors wish to acknowledge Professor Lois Salamonsen for critical appraisal of this manuscript, and Mrs Sue Panckridge for assistance with figure preparation. This work was supported by a CONRAD research grant (\#CIG-08-125 to GN), a National Health and Medical Research Council Senior Research Fellowship (\#494808 to GN), and by the Victorian Government's Operational Infrastructure Support Program.}

\section{Author details \\ ${ }^{1}$ Prince Henrys Institute of Medical Research, 246 Clayton Road, Clayton, Victoria 3168, Australia. ²Department of Biochemistry and Molecular Biology, Monash University, Clayton, Victoria 3800, Australia. ${ }^{3}$ Key Laboratory of Contraceptive Drugs and Devices of National Population and Family Planning Committee, Shanghai Institute of Planned Parenthood Research, 2140 Xie Tu Road, Shanghai 200032, China.}

\section{Authors' contributions}

PKN carried out the RNA and immunohistological analyses, and assisted in the drafting of the manuscript. ZS carried out the animal studies and assisted in the tissue collection SH carried out the protein analyses YL assisted with the RNA and immunohistological analyses. JW supervised the animal studies and assisted in the tissue collection GN conceived and designed the project, supervised the overall project and prepared the manuscript. All authors read and approved the final manuscript.

\section{Author Information}

Correspondence to: Guiying Nie, Ph.D., Prince Henry's Institute of Medical Research, 246 Clayton Road, Clayton, Victoria 3168, Australia. E-mail: http:// guiying.nie@princehenrys.org. Phone: +61 39594 4380. Fax: +61 395946125.

\section{Competing interests}

The authors declare that they have no competing interests.

Received: 11 February 2011 Accepted: 6 April 2011

Published: 6 April 2011

\section{References}

1. Salamonsen LA, Nie G, Hannan NJ, Dimitriadis E: Society for Reproductive Biology Founders' Lecture 2009. Preparing fertile soil: the importance of endometrial receptivity. Reprod Fertil Dev 2009, 21(7):923-934.
2. Norwitz ER, Schust DJ, Fisher SJ: Implantation and the survival of early pregnancy. N Engl J Med 2001, 345(19):1400-1408.

3. Wilcox AJ, Weinberg CR, O'Connor JF, Baird DD, Schlatterer JP, Canfield RE, Armstrong EG, Nisula BC: Incidence of early loss of pregnancy. N Engl J Med 1988, 319(4):189-194.

4. Dimitriadis E, Menkhorst E, Salamonsen LA, Paiva P: Review: LIF and IL11 in trophoblast-endometrial interactions during the establishment of pregnancy. Placenta 2010, 31(Suppl):S99-104.

5. Bassi DE, Fu J, Lopez de Cicco R, Klein-Szanto AJ: Proprotein convertases: "master switches" in the regulation of tumor growth and progression. Mol Carcinog 2005, 44(3):151-161.

6. Rockwell NC, Thorner JW: The kindest cuts of all: crystal structures of Kex2 and furin reveal secrets of precursor processing. Trends Biochem Sci 2004, 29(2):80-87.

7. Scamuffa N, Siegfried G, Bontemps Y, Ma L, Basak A, Cherel G, Calvo F, Seidah NG, Khatib AM: Selective inhibition of proprotein convertases represses the metastatic potential of human colorectal tumor cells. J Clin Invest 2008, 118(1):352-363.

8. Nie G, Li Y, Wang M, Liu YX, Findlay JK, Salamonsen LA: Inhibiting uterine PC6 blocks embryo implantation: an obligatory role for a proprotein convertase in fertility. Biol Reprod 2005, 72(4):1029-1036.

9. Nie GY, Li Y, Minoura H, Findlay JK, Salamonsen LA: Specific and transient up-regulation of proprotein convertase 6 at the site of embryo implantation and identification of a unique transcript in mouse uterus during early pregnancy. Biol Reprod 2003, 68(2):439-447.

10. Tang M, Mikhailik A, Pauli I, Giudice LC, Fazelabas AT, Tulac S, Carson DD, Kaufman DG, Barbier C, Creemers JW, et al: Decidual differentiation of stromal cells promotes Proprotein Convertase 5/6 expression and lefty processing. Endocrinology 2005, 146(12):5313-5320.

11. Heng S, Paule S, Hardman B, Li Y, Singh H, Rainczuk A, Stephens AN, Nie G: Posttranslational activation of bone morphogenetic protein 2 is mediated by proprotein convertase 6 during decidualization for pregnancy establishment. Endocrinology 2010, 151(8):3909-3917.

12. Nie G, Findlay JK, Salamonsen LA: Identification of novel endometrial targets for contraception. Contraception 2005, 71(4):272-281.

13. Freyer C, Kilpatrick LM, Salamonsen LA, Nie G: Pro-protein convertases (PCs) other than PC6 are not tightly regulated for implantation in the human endometrium. Reproduction 2007, 133(6):1189-1197.

14. Okada H, Nie G, Salamonsen LA: Requirement for proprotein convertase $5 / 6$ during decidualization of human endometrial stromal cells in vitro. Clin Endocrinol Metab 2005, 90(2):1028-1034.

15. Genbacev OD, Prakobphol A, Foulk RA, Krtolica AR, llic D, Singer MS Yang ZQ, Kiessling LL, Rosen SD, Fisher SJ: Trophoblast L-selectinmediated adhesion at the maternal-fetal interface. Science 2003, 299(5605):405-408.

16. Jones CJP, Aplin JD: Reproductive Glycogenetics - A critical factor in pregnancy success and species hybridisation. Placenta 2009, 30(3):216-219.

17. Lee KY, DeMayo FJ: Animal models of implantation. Reproduction 2004, 128(6):679-695.

18. Yang ZM, Chen DB, Le SP, Harper MJ: Differential hormonal regulation of leukemia inhibitory factor (LIF) in rabbit and mouse uterus. Mol Reprod Dev 1996, 43(4):470-476.

19. Davies J, Hoffman LH: Studies on the progestational endometrium of the rabbit. I. Light microscopy, day 0 to day 13 of gonadotrophin-induced pseudopregnancy. Am J Anat 1973, 137(4):423-445.

20. Apparao KB, Illera MJ, Beyler SA, Olson GE, Osteen KG, Corjay MH, Boggess K, Lessey BA: Regulated expression of osteopontin in the periimplantation rabbit uterus. Biol Reprod 2003, 68(5):1484-1490.

21. Hoffman LH, Olson GE, Carson DD, Chilton BS: Progesterone and implanting blastocysts regulate Muc1 expression in rabbit uterine epithelium. Endocrinology 1998, 139(1):266-271.

22. Illera MJ, Lorenzo PL, Gui YT, Beyler SA, Apparao KB, Lessey BA: A role for alphavbeta3 integrin during implantation in the rabbit model. Biol Reprod 2003, 68(3):766-771.

23. Klonisch T, Wolf $P$, Hombach-Klonisch S, Vogt S, Kuechenhoff A, Tetens F, Fischer B: Epidermal growth factor-like ligands and erbB genes in the peri-implantation rabbit uterus and blastocyst. Biol Reprod 2001, 64(6):1835-1844

24. Barbero P, Rovere C, De Bie I, Seidah N, Beaudet A, Kitabgi P: PC5-Amediated processing of pro-neurotensin in early compartments of the 
regulated secretory pathway of PC5-transfected PC12 cells. J Biol Chem 1998, 273:25339-25346.

25. Carson DD, Bagchi I, Dey SK, Enders AC, Fazleabas AT, Lessey BA, Yoshinaga K: Embryo implantation. Dev Biol 2000, 223(2):217-237.

26. Kalus I, Schnegelsberg B, Seidah NG, Kleene R, Schachner M: The proprotein convertase PC5A and a metalloprotease are involved in the proteolytic processing of the neural adhesion molecule L1. J Biol Chem 2003, 278(12):10381-10388.

27. Lissitzky JC, Luis J, Munzer JS, Benjannet S, Parat F, Chretien M, Marvaldi J Seidah NG: Endoproteolytic processing of integrin pro-alpha subunits involves the redundant function of furin and proprotein convertase (PC) $5 \mathrm{~A}$, but not paired basic amino acid converting enzyme (PACE) 4, PC5B or PC7. Biochem J 2000, 346(Pt 1):133-138.

28. Stawowy P, Kallisch H, Veinot JP, Kilimnik A, Prichett W, Goetze S, Seidah NG, Chretien M, Fleck E, Graf K: Endoproteolytic activation of alpha (v) integrin by proprotein convertase PC5 is required for vascular smooth muscle cell adhesion to vitronectin and integrin-dependent signaling. Circulation 2004, 109(6):770-776.

29. Mayer G, Hamelin J, Asselin MC, Pasquato A, Marcinkiewicz E, Tang M, Tabibzadeh S, Seidah NG: The regulated cell surface zymogen activation of the proprotein convertase PC5A directs the processing of its secretory substrates. J Biol Chem 2008, 283(4):2373-2384.

30. Seidah NG, Mayer G, Zaid A, Rousselet E, Nassoury N, Poirier S, Essalmani R, Prat $A$ : The activation and physiological functions of the proprotein convertases. Int J Biochem Cell Biol 2008, 40(6-7):1111-1125.

31. Das SK, Wang XN, Paria BC, Damm D, Abraham JA, Klagsbrun M, Andrews GK, Dey SK: Heparin-binding EGF-like growth factor gene is induced in the mouse uterus temporally by the blastocyst solely at the site of its apposition: a possible ligand for interaction with blastocyst EGF- receptor in implantation. Development 1994, 120(5):1071-1083.

doi:10.1186/1477-7827-9-43

Cite this article as: Nicholls et al: Embryo implantation is closely associated with dynamic expression of proprotein convertase $5 / 6$ in the rabbit uterus. Reproductive Biology and Endocrinology 2011 9:43.

\section{Submit your next manuscript to BioMed Central and take full advantage of:}

- Convenient online submission

- Thorough peer review

- No space constraints or color figure charges

- Immediate publication on acceptance

- Inclusion in PubMed, CAS, Scopus and Google Scholar

- Research which is freely available for redistribution

Submit your manuscript at www.biomedcentral.com/submit
Biomed Central 